\title{
Laparoscopic surgery for gastric cancer: preliminary experience
}

\author{
Fabio Carboni, Pasquale Lepiane, Roberto Santoro, Pietro Mancini, Riccardo Lorusso, \\ and EUgEnio SANTORO \\ Department of Oncologic Surgery, Division of Digestive Surgery and Liver Transplantation, Regina Elena Cancer Institute, \\ via Elio Chianesi 53, 00144, Rome, Italy
}

\begin{abstract}
Background. Laparoscopic surgery for gastric cancer (GC) was introduced in the past decade because it was considered less invasive than open surgery, resulting in less postoperative pain, faster recovery, and improved quality of life. Several studies have demonstrated the safety and feasibility of this procedure. We analyzed our preliminary experience with this procedure.

Methods. From November 2003 to December 2004, 20 patients affected by gastric adenocarcinoma were operated on with a totally laparoscopic or laparoscopic-assisted approach. This series included 10 women and 10 men, aged from 34 to 75 years. Procedures consisted of eight total gastrectomies, three subtotal Billroth I and seven Billroth II gastrectomies, one proximal gastrectomy, and one wedge resection. According to the TNM classification, we observed five patients at stage Ia, four at stage Ib, three at stage II, one at stage IIIa, two at stage IIIb, and five at stage IV.

Results. In all patients the procedures were completed without any conversion. Operative time ranged from 150 to $300 \mathrm{~min}$. The number of dissected lymph nodes ranged from 23 to 47. No mortality was observed. Overall morbidity rate was $10 \%$ (two cases), with one enteric fistula and one esophagojejunal anastomotic leakage associated with pancreatitis. Excluding these two patients, postoperative stay was between 12 and 20 days.

Conclusions. Even though accompanied by a difficult learning curve, safety and feasibility are widely demonstrated, but a skilled and experienced surgeon is required. Accurate selection of patients is mandatory and curative resection is achievable in cases where GC is not advanced.
\end{abstract}

Key words Gastric cancer · Laparoscopic surgery · Subtotal gastrectomy $\cdot$ Total gastrectomy $\cdot$ Lymph node dissection

Offprint requests to: $\mathrm{F}$. Carboni

Received: February 2, 2005 / Accepted: March 1, 2005

\section{Introduction}

Since Kitano et al. first described laparoscopic surgery for gastric cancer (GC) in 1994 [1], its safety and feasibility have been increasingly demonstrated. In several series, it also has resulted in less postoperative pain, faster recovery, shorter hospital stay, and better quality of life compared with open surgery [2-6].

From an oncological point of view, curative resections with similar survival rates have been obtained in early gastric cancer (EGC) cases [7-11]. However, long-term results in more advanced cases are not still available.

After gaining wide experience with both GC and oncologic laparoscopic surgery, we recently decided to perform laparoscopic resections for selected GC patients. Here we report the preliminary results of our experience with this procedure.

\section{Patients and methods}

Of 930 patients admitted for gastric procedures in a 25 year period (1979-2004), 853 (91.7\%) were operated on for adenocarcinoma and entered in a prospectively collected database. Between November 2003 and December 2004, 20 of 66 patients with GC who underwent gastric surgery were considered candidates for laparoscopic resection based on our inclusion criteria (Table 1).

The series included 12 women and 8 men, median age 59 years (range 34-75 years). Preoperative work-up included endoscopy with biopsy, abdominal ultrasound, and computed tomography scan in all cases. An upper gastrointestinal series was performed occasionally, while no endoscopic ultrasonography was used. Intraoperative gastroscopy was used to identify small intraluminal lesions in selected cases. 
Table 1. Inclusion criteria in the laparoscopic surgery in our institute

- Body mass index $<30$

- ASA (American Society of Anesthesiology) score I or II

- No previous major abdominal surgery

- Preoperative clinical staging showing a feasible curative D2 gastrectomy as for open surgery (T1-3 N0-1) or a palliative resection for advanced cases

Table 2. Pathological staging

\begin{tabular}{lcc}
\hline Stage & TNM & Patients \\
\hline Ia & $\mathrm{T}_{1} \mathrm{~N}_{0} \mathrm{M}_{0}$ & 5 \\
Ib & $\mathrm{T}_{2} \mathrm{~N}_{0} \mathrm{M}_{0}$ & 4 \\
II & $\mathrm{T}_{2} \mathrm{~N}_{1} \mathrm{M}_{0}$ & 2 \\
II & $\mathrm{T}_{3} \mathrm{~N}_{0} \mathrm{M}_{0}$ & 1 \\
IIIa & $\mathrm{T}_{3} \mathrm{~N}_{1} \mathrm{M}_{0}$ & 1 \\
IIIb & $\mathrm{T}_{3} \mathrm{~N}_{2} \mathrm{M}_{0}$ & 2 \\
IV & $\mathrm{T}_{2} \mathrm{~N}_{3} \mathrm{M}_{0}$ & 2 \\
IV & $\mathrm{T}_{3} \mathrm{~N}_{3} \mathrm{M}_{0}$ & 3 \\
\hline
\end{tabular}

Procedures consisted of eight total gastrectomies (TG), three subtotal Billroth I (BI) and seven Billroth II (BII) distal gastrectomies (STG), one proximal gastrectomy (PG), and one wedge resection (WR). Excluding the last patient, limited D2 lymph node dissection (stations 1 to 8 ) was performed in all patients, with standard D2 dissection performed for curative intention in selected cases. Pathological staging according to the 1997 TNM classification [12] is reported in Table 2.

In brief, surgical technique consisted of introduction of a laparoscope through a periumbilical port and the use of four trocars $(10 \mathrm{~mm}$ each). Hemostasis and dissection were accomplished by Ligasure Atlas (Valleylab, Tyco, Boulder, CO, USA) and surgical clips. A small $(4-5 \mathrm{~cm})$ incision was used for extraction of the specimen and to perform the anastomosis in some cases. BII reconstruction was always extracorporeal handsewn, while BI reconstruction and esophagojejunal anastomosis after TG were intracorporeal using circular staplers, totally laparoscopic or through the small incision. Informed consent was obtained from each patient.

\section{Results}

In all patients the procedures were completed without any conversion. Operating time ranged from 150 to $300 \mathrm{~min}$, depending on the type of operation, and was higher at the beginning of the experience. Intraoperative blood loss was always less than $200 \mathrm{ml}$, and no transfusion was required.

Excluding the patient who underwent WR, the number of dissected lymph nodes ranged from 23 to 47 .
Table 3. Operative results

\begin{tabular}{lc} 
Factor & Number or range \\
\hline Surgical procedure & \\
TG & 8 \\
STG BI & 3 \\
STG BII & 7 \\
PG & 1 \\
WR & 1 \\
Mean operating time (min) & $150-300$ \\
Number of dissected lymph nodes & $23-47$ \\
Conversion & 0 \\
Morbidity & $2(10 \%)$ \\
Mortality & 0 \\
Mean postoperative stay (days) & $12-20$ \\
\hline TG, total gastrectomy; STG BI, subtotal Billroth I gastrectomy; STG \\
BII, subtotal Billroth II gastrectomy; PG, proximal gastrectomy; WR, \\
wedge resection
\end{tabular}

Mortality was nil. Overall morbidity rate was $10 \%$ (two cases). In one patient, who underwent a Billroth I STG for a stage IIIB (T3N2M0) distal cancer at the beginning of our experience, an enteric fistula from the left colonic flexure occurred, and it was successfully managed conservatively after 60 days. In the other patient, who underwent a palliative TG for a stage IV (T3N3M0) diffuse cancer, an esophagojejunal anastomotic leakage associated with pancreatitis occurred, and it also was managed conservatively, after 47 days. Excluding these two cases, postoperative stay was between 12 and 20 days. Operative results are reported in Table 3 .

\section{Discussion}

In the past decade, minimally invasive surgery for the treatment of GC has been increasingly used. An international review showed a total of 118 laparoscopic gastric procedures performed up to 1994 , with only 46 $(38 \%)$ of these for cancer [13]. Since then, owing to the introduction of new technical devices such as the bipolar diathermy system or coagulating shears for dissection, laparoscopy has gained worldwide acceptance in clinical practice at specialized institutions for gastric cancer surgery. Considering the period from 1999 to 2003, more than 550 laparoscopic gastric resections for cancer have been reported in major literature, coming mostly from Eastern series [2-11,14-18].

Safety and feasibility of the laparoscopic approach have been widely demonstrated. Recent series showed identical results in terms of postoperative mortality and morbidity rates as well as operative parameters (operative time, blood loss, transfusions) compared with open surgery [2-6]. Moreover, reported clinical advantages are less postoperative pain, reduced inflammatory re- 
sponse, faster recovery of intestinal function, less impaired nutrition and pulmonary function, shorter hospital stay, and better quality of life [2-11].

From an oncological point of view, with experienced surgeons the number of dissected lymph nodes is adequate, and long-term results for EGC have been as good as those after open surgery [7-11,18-20]. At the same time, there are only occasional reports of laparoscopic curative resections for more advanced cases $[5,6,9,14,15,18,19]$. According to Miura et al., the extent of lymphadenectomy achieved by current laparoscopic procedures approaches the standard for accurate staging, although performing extended resections remains a challenge [20].

The technical procedure usually consists of a complete intracorporeal dissection with subsequent intra- or extracorporeal anastomosis. As confirmed by our experience, laparoscopic STG is the most commonly performed procedure. A Billroth I gastroduodenostomy with intraabdominal anastomosis can be performed using a circular stapler, but a Billroth II gastrojejunostomy using linear staplers is often preferred in the totally laparoscopic approach. However, the extraabdominal approach with a small incision is very diffuse for both reconstructions. By contrast, TG is a technically demanding and time-consuming procedure, requiring a very skilled and experienced surgeon. From 1999 to 2003 , only $36(6.5 \%)$ TGs were reported in the literature, most being laparoscopic-assisted [14,16$18,19,21]$. In our experience, this procedure was associated with higher operating time and blood loss and longer hospital stay than the other laparoscopic procedures, but it was mostly performed for advanced GC cases with palliative intent. Finally, as occurred in our series, laparoscopic PG for EGC is still reported occasionally $[16,19,21,22]$.

In conclusion, even though accompanied by a difficult learning curve, safety and feasibility of the procedure are widely demonstrated. A skilled and experienced surgeon is required, and accurate selection of patients is mandatory. Nowadays, EGC (T1-2 N0) should be considered a selective indication for a curative resection with a totally laparoscopic approach. Selected advanced cases (T3-4 N+) may also be candidates for a palliative resection, better accomplished with a laparoscopicassisted approach.

\section{References}

1. Kitano S, Iso Y, Moriyama M, Sugimachi K. Laparoscopicassisted Billroth I gastrectomy. Surg Laparosc Endosc 1994;2: $146-8$.

2. Adachi Y, Shiraishi N, Shiromizu A, Bandoh T, Aramaki M, Kitano S. Laparoscopy-assisted Billroth I gastrectomy compared with conventional open gastrectomy. Arch Surg 2000;135:806-10.
3. Kitano S, Shiraishi N, Fujii K, Yasuda K, Inomata M, Adachi Y. A randomized controlled trial comparing open vs laparoscopyassisted distal gastrectomy for the treatment of early gastric cancer: an interim report. Surgery 2002;13:S306-11.

4. Yano H, Monden T, Kinuta M, Nakano Y, Tono T, Matsui S, et al. The usefulness of laparoscopy-assisted distal gastrectomy for early gastric cancer. Gastric Cancer 2001;4:93-7.

5. Ballesta Lopez C, Ruggiero R, Poves I, Bettonica C, Procaccini E. The contribution of laparoscopy to the treatment of gastric cancer. Surg Endosc 2002;16:616-9.

6. Weber KJ, Reyes CD, Gagner M, Divino CM. Comparison of laparoscopic and open gastrectomy for malignant disease. Surg Endosc 2003;17:968-71.

7. Asao T, Hosouchi $Y$, Nakabayashi T, Naga N, Mochiki E, Kuwano H. Laparoscopically assisted total or distal gastrectomy with lymph node dissection for early gastric cancer. Br J Surg 2001;88:128-32.

8. Kitano S, Shiraishi N, Kakisako K, Yasuda K, Inomata M, Adachi Y. Laparoscopy-assisted Billroth I gastrectomy (LADG) for cancer: our 10 years' experience. Surg Laparosc Endosc Percutan Tech 2002;12:204-7.

9. Tanimura S, Higashino M, Fukunaga Y, Osugi H. Laparoscopic distal gastrectomy with regional lymph node dissection for gastric cancer. Surg Endosc 2003;17:758-62.

10. Shimizu S, Noshiro H, Nagai E, Uchiyama A, Tanaka M. Laparoscopic gastric surgery in a Japanese institution: analysis of the initial 100 procedures. J Am Coll Surg 2003;197:372-7

11. Fujiwara M, Kodera Y, Kasai Y, Kanyama Y, Hibi K, Ito K, et al. Laparoscopy-assisted distal gastrectomy with systemic lymph node dissection for early gastric carcinoma: a review of 43 cases. J Am Coll Surg 2003;196:75-81.

12. Sobin LH, Wittekind C. TNM classification for malignant tumors. 5th ed. New York: Wiley; 1997. p. 59-62.

13. Goh PMY, Alponat A, Mak K, Kum CK. Early international results of laparoscopic gastrectomies. Surg Endosc 1997;11:6502.

14. Azagra JS, Goergen M, De Simone P, Ibanez-Aguirre J. Minimally invasive surgery for gastric cancer. Surg Endosc 1999; 13:351-7.

15. Goh PMY, Khan AZ, So JBY, Lomanto D, Cheah WK, Muthiah $\mathrm{R}$, et al. Early experience with laparoscopic radical gastrectomy for advanced gastric cancer. Surg Laparosc Endosc Percutan Tech 2001;11:83-7.

16. Mochiki E, Kamimura H, Haga N, Asao T, Kuwano H. The technique of laparoscopically assisted total gastrectomy with jejunal interposition for early gastric cancer. Surg Endosc 2002; 16:540-4.

17. Kim YW, Han HS, Fleischer GD. Hand-assisted laparoscopic total gastrectomy. Surg Laparosc Endosc Percutan Tech 2003;13: 26-30.

18. Uyama I, Sugioka A, Matsui H, Fujita J, Komori Y, Hasumi A. Laparoscopic D2 lymph node dissection for advanced gastric cancer located in the middle or lower third portion of the stomach. Gastric Cancer 2000;3:50-5.

19. Uyama I, Sugioka A, Sakurai Y, Komori Y, Hanai T, Matsui H, et al. Hand-assisted laparoscopic function-preserving and radical gastrectomies for advanced-stage proximal gastric cancer. J Am Coll Surg 2004;199:508-15.

20. Miura S, Kodera Y, Fujiwara M, Ito S, Mochizuki Y, Yamamura $\mathrm{Y}$, et al. Laparoscopy-assisted distal gastrectomy with systemic lymph node dissection: a critical reappraisal from the viewpoint of lymph node retrieval. J Am Coll Surg 2004;198:933-8.

21. Tanimura S, Higashino M, Fukunaga Y, Osugi H. Laparoscopic gastrectomy with regional lymph node dissection for upper gastric cancer. Gastric Cancer 2003;6:64-8.

22. Kitano S, Adachi Y, Shiraishi N, Suematsu T, Bando T. Laparoscopic-assisted proximal gastrectomy for early gastric carcinomas. Surg Today 1999;29:389-91. 